\title{
Effect of Fin Orientation and Length on the Rayleigh-Benard Convection
}

\author{
E. Evren Selamet, A. Selamet and R. Dehner \\ Department of Mechanical and Aerospace Engineering, Ohio State University, Columbus OH 43210, USA
}

Received: February 07, 2017 / Accepted: February 13, 2017 / Published: May 31, 2017.

\begin{abstract}
Natural convection driven by the temperature difference of horizontal top and bottom surfaces of an enclosure containing air, $\operatorname{Pr}=0.7$, and fins of different arrangements at different lengths is studied numerically for $\mathrm{Ra}=10^{5}$ and $5 \times 10^{5}$. Evolution of heat transfer rates (Nusselt number) is illustrated along with various, steady or unsteady, cellular flow structures and temperature patterns. The effect of fin length and placement on flow regime and heat transfer is established. Different fin orientations at the walls are observed to introduce considerable unsteadiness in some cases, requiring close investigation in order to design systems for specific purposes.
\end{abstract}

Key words: Rayleigh-Benard convection, fin, instability.

\section{Nomenclature}

$\begin{array}{ll}\mathrm{g} & \text { Gravitational acceleration } \\ \mathrm{k} & \text { Thermal conductivity } \\ \ell & \text { Nondimensional fin length } \\ L & \text { Width of square cavity } \\ \mathrm{Nu} & \text { Local Nusselt number } \\ p & \text { Nondimensional pressure } \\ \mathrm{Pr} & \text { Prandtl number } \\ \mathrm{Ra} & \text { Rayleigh number } \\ \mathrm{s} & \text { Nondimensional fin distance from wall } \\ t & \text { Nondimensional time } \\ u & \text { Nondimensional horizontal velocity } \\ v & \text { Nondimensional vertical velocity } \\ x, y & \text { Nondimensional coordinates }\end{array}$

Greek Letters

$\begin{array}{ll}\alpha & \text { Thermal diffusivity } \\ \beta & \text { Coefficient of thermal expansion } \\ \Delta & \text { Difference } \\ \theta & \text { Nondimensional temperature } \\ v & \text { Kinematic viscosity } \\ \rho & \text { Density } \\ \Psi & \text { Stream function }\end{array}$

Corresponding author: Emel Evren Selamet, Ph.D., research scientist, research fields: heat transfer, computational fluid dynamics, internal combustion engine simulations.

\author{
Subscript

$\begin{array}{ll}\mathrm{c} & \text { Cold } \\ \mathrm{f} & \text { Fin } \\ \mathrm{h} & \text { Hot }\end{array}$ \\ Superscript \\ * Dimensional quantity
}

\section{Introduction}

Steady or unsteady natural convection in enclosures has been the subject of extensive experimental and numerical investigations. Thermal flow induced by the heated bottom surface in enclosures [classic RB (Rayleigh-Benard) convection] has been studied for several decades [1-14]. Many engineering applications involve also the suppression or enhancement of heat transfer. One approach to achieve this objective has been the extension of internal wall area by fins. The increase of internal surface area may have a favorable or detrimental effect on heat transfer, requiring a careful examination of the pertinent parameters, such as fin spacing and sizing. Numerous studies have investigated the impact of fins in enclosures with a 
temperature gradient between the vertical walls along with the insulated top and bottom surfaces. Examples include: a single fin on the hot wall [15-18], a single fin on the insulated top wall [19], a single fin attached to either vertical (hot) or bottom (insulated) wall [20]. In contrast to these studies with laterally heated cavities, however, the research on augmentation or suppression of heat transfer in RB convection through fins is relatively limited. Refs. [21-23] are among the early works which have concentrated on horizontal rectangular fins in configurations heated from the bottom walls. The more recent studies include, for example, Ref. [24] which has examined computationally the influence of transverse fins attached to the heated bottom wall with emphasis on the impact of fin size, fin spacing, and the thermal conductivity of fin material for Rayleigh numbers (Ra) up to $6 \times 10^{4}$. Another computational effort [25] has attached a number of fins to the bottom (hot) surface and elaborated on the effectiveness of finned surface for $\mathrm{Ra}<3 \times 10^{4}$. Since such a Ra range is relatively low, these guidelines, while useful, apply only to steady flows. Placing fins at the walls with higher Ra introduces considerable unsteadiness in many cases, requiring close attention to the convective instabilities in order to design systems either to enhance or suppress heat transfer. The present study, therefore, analyzes the behavior of flow patterns and heat transfer in a square cavity filled with air and comparably stable or unstable solutions for fin arrangements which have not been considered thus far in the literature.

Following this introduction, Section 2 defines the geometry and introduces the governing equations, Section 3 provides a validation of the approach, followed by the detailed results and discussion in Section 4, and concluding remarks in Section 5.

\section{Definition and Formulation of the Problem}

The present study considers a two-dimensional square cavity of width and height of $L$, as shown in Fig. 1. The vertical walls are thermally insulated and the horizontal walls are kept at temperatures of $T_{\mathrm{h}}$ (hot bottom) and $T_{\mathrm{c}}$ (cold top), respectively. Unsteady governing equations are employed here since the evolution of flow pattern and the associated time-dependent behavior can only be captured by using time-stepping computations. In terms of the following non-dimensional variables $x=x^{*} / L, y=y^{*} / L$; $u=u^{*} L / \alpha, v=v^{*} L / \alpha ; t=t^{*} \alpha / L^{2} ; p=p^{*} L^{2} /\left(\rho \alpha^{2}\right) ; \Theta$ $=\left(T-T_{c}\right) /\left(T_{h}-T_{c}\right)$, where $x^{*}, y^{*}$ are the coordinates; $u^{*}, v^{*}$ the velocities; $t^{*}$ the time; $p^{*}$ the pressure; $T$ the temperature; the governing equations in primitive variables for mass, $\mathrm{x}$ - and $\mathrm{y}$-momentum, and energy may be written for buoyancy-driven incompressible fluids as

$$
\begin{gathered}
\frac{\partial u}{\partial x}+\frac{\partial v}{\partial y}=0 \\
\frac{\partial u}{\partial t}+\frac{\partial u^{2}}{\partial x}+\frac{\partial u v}{\partial y}=-\frac{\partial p}{\partial x}+\operatorname{Pr} \nabla^{2} u \\
\frac{\partial v}{\partial t}+\frac{\partial u v}{\partial x}+\frac{\partial v^{2}}{\partial y}=-\frac{\partial p}{\partial y}+\operatorname{Pr} \nabla^{2} v \\
+\operatorname{Ra} \operatorname{Pr} \Theta \\
\frac{\partial \Theta}{\partial t}+\frac{\partial u \Theta}{\partial x}+\frac{\partial v \Theta}{\partial y}=\nabla^{2} \Theta
\end{gathered}
$$

where, $\nabla^{2}$ is the two-dimensional Laplacian; $\operatorname{Pr}=v / \alpha$, the Prandtl number; $\mathrm{Ra}=g \beta \Delta T L^{3} / v \alpha, g$ being the gravitational acceleration, $\beta$ the coefficient of thermal expansion of the fluid, $\Delta T$ the temperature difference between top and bottom walls; $v$ the kinematic viscosity; and $\alpha$ the thermal diffusivity. The no slip boundary conditions are applied to the velocity. Incompressible fluid is considered and the Boussinesq approximation which treats density as a constant in all equations except the gravitational force term in the momentum equation, is assumed to be valid. Even though the computations are performed by using primitive variables, flow field results are presented in terms of the stream function $\Psi(u=\partial \Psi / \partial \mathrm{y}, v=$ $-\partial \Psi / \partial \mathrm{x})$. No slip boundary conditions are imposed on all walls and fins. The governing equations with 


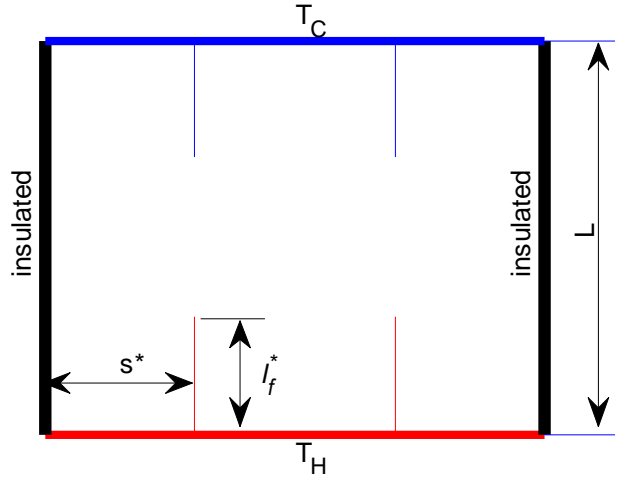

Fig. 1 Schematic configuration of the enclosure [sample case: two fins at the top, two fins at the bottom $(2 \mathrm{~T}+2 \mathrm{~B})]$.

primitive variables are solved on a staggered grid by applying the Godunov scheme to convective terms and centered finite difference to diffusive terms. Details of the method are explained in an earlier work of the lead author [26].

In the present configuration, six fin arrangements are considered: two fins at the bottom wall (2B); two fins at the top wall (2T); two fins at the left wall (2L); two fins at the right wall (2R); two fins at the left wall and also two fins at the right wall $(2 \mathrm{~L}+2 \mathrm{R})$; and two fins at the top as well as two fins at the bottom wall $(2 \mathrm{~T}+2 \mathrm{~B})$. Results for each case are investigated for fins at two different sets of distances from a wall; $s=$ [0.23, 0.77] (uneven spacing) and [0.33, 0.67] (even spacing), with $s=s^{*} / L$ denoting the (nondimensionalized) distance from wall; and four fin lengths of $l_{f}=l_{f}^{*} / L$ of $0.1,0.2,0.25$, and $0.35\left(s^{*}\right.$ and $l_{f}^{*}$ are shown in Fig. 1). Fins are made of highly conductive material, thus their temperatures are essentially the same as the wall to which they are attached.

\section{Validation for an Enclosure with Single} Fin

Although the validity of the code is assessed earlier for a number of different cases in Refs. [26, 27], an additional attempt is made here by considering studies that more closely represent the present enclosure. The results from the present predictions are compared qualitatively with those from the earlier works of [25] and [28] which studied numerically 3D natural convection in a cubical enclosure with a single fin placed at the bottom (hot) surface. As a representative case, Fig. 2 shows the flow field in terms of streamlines and isotherms for $\mathrm{Ra}=5 \times 10^{3}$ (a) in the absence of any fin and (b) for a fin length of 0.25 . Fig. 3 illustrates the same fields for $\mathrm{Ra}=10^{4}$ and $10^{5}$ for a fin length of 0.5 which show trends consistent with the findings of both Refs. [25] and [28]. Fig. 4 provides a quantitative comparison of the present results with Ref. [28] in terms of Nusselt number $\mathrm{Nu}$ - the ratio of heat transferred by convection to that of conduction, or, alternatively the dimensionless temperature gradient-versus Ra for a fin placed in the middle of bottom surface, and of length 0.5 . The deviation between two sets of results in Fig. 4 may be attributed to three-dimensional effects.

\section{Results and Discussion}

The effects of fin geometry (length, location, and spacing in between) on heat transfer are then examined with highly conductive (thus isothermal at the base wall temperature) and varying number ( 2 or 4 ) of fins. Steady or unsteady solution is obtained for Ra $=10^{5}$ and $5 \times 10^{5}$. Primary interest here is to study the unsteady nature of the flow and thermal fields and the oscillatory convection in terms of the evolution of $\mathrm{Nu}$. The grid independency of the results has been checked and the mesh size of $99 \times 99$ is found to be sufficient.

\subsection{Results for $R a=10^{5}$}

\subsubsection{Fins Located Unevenly, $s=[0.23,0.77]$}

Fig. 5 shows the evolution of $\mathrm{Nu}$ for $\mathrm{Ra}=10^{5}$ with no-fin (designated by yellow), and for fin lengths of (a) $l_{f}=0.1$, (b) 0.2 , (c) 0.25 , and (d) 0.35; all with a placement of $s=[0.23,0.77]$; and six fin arrangements were described in Section 2. Nu reaches the steady state at a value smaller than that of no-fin case for all fin arrangements and lengths. This suggests that the blocking effect of fins on flow overtakes the heat transfer by highly conductive fins. 
Since the steady state is reached, final values of $\mathrm{Nu}$ are also shown in Fig. 6 as a function of fin length for those arrangements to readily illustrate the effect of fin length. With two top fins (2T), Nu decreases least relative to the no-fin case for all lengths. $\mathrm{Nu}$ decreases with increasing length of $l_{f}=0.1,0.2$, and 0.25 for all
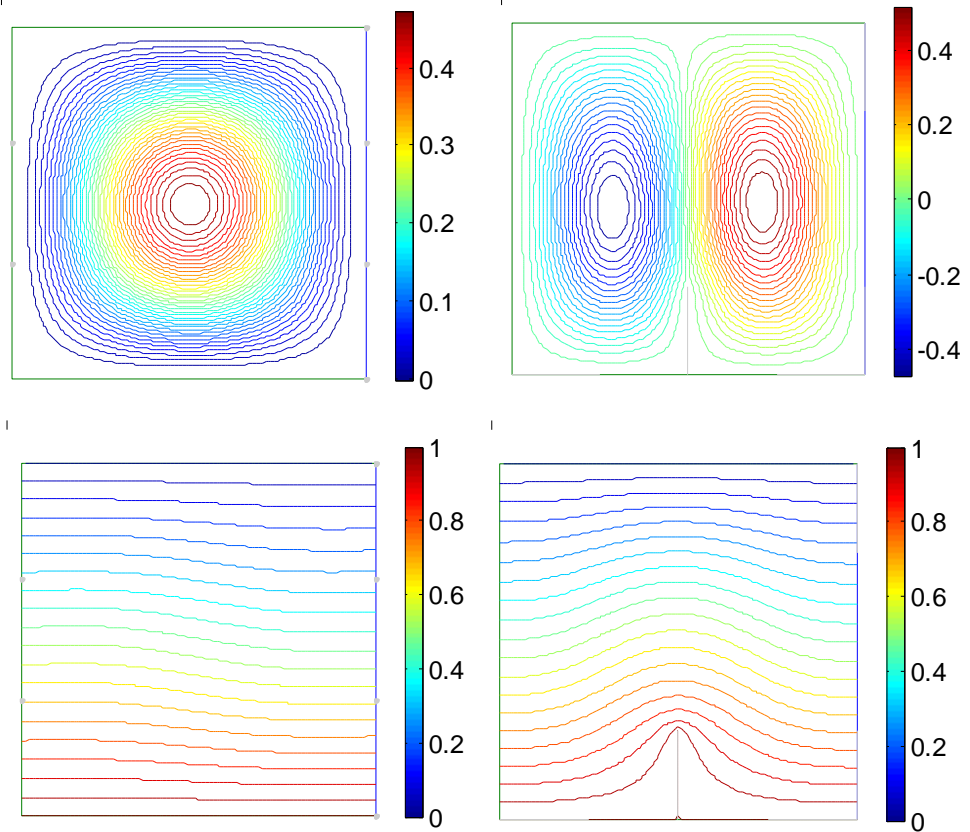

(a)

Fig. 2 Streamlines (top) and isotherms (bottom) at Ra $=5 \times 10^{3}$ : (a) in the absence of fin, (b) $l_{f}=0.25$.
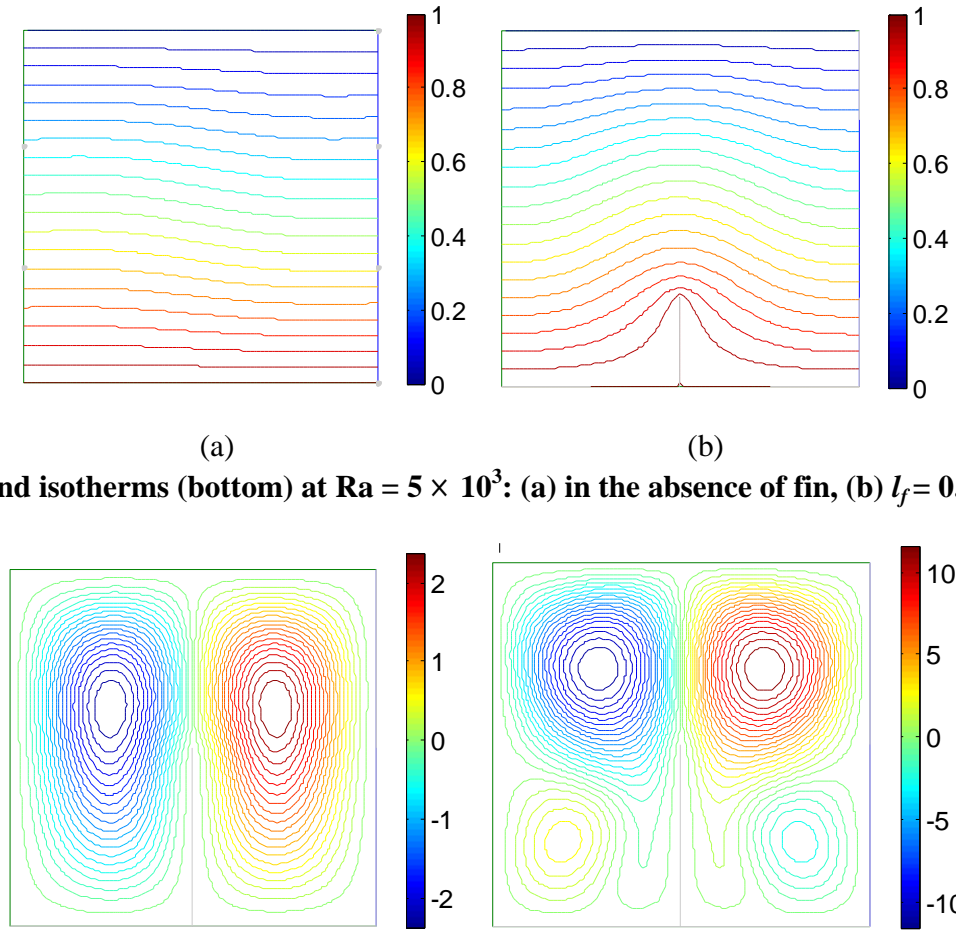

(b)

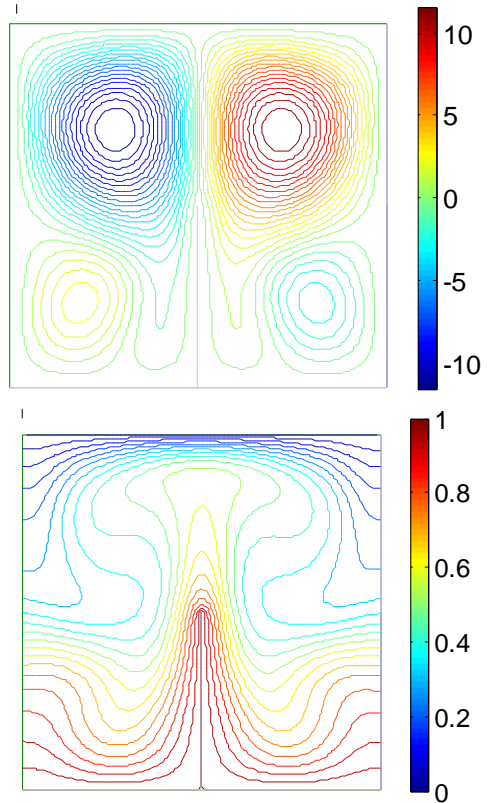

(b)

(a)

Fig. 3 Streamlines (top) and isotherms (bottom) for a fin length of $0.5, \operatorname{Pr}=0.71$ : $(a) \operatorname{Ra}=10^{4}$, and $(b) \operatorname{Ra}=10^{5}$. located at the top and bottom walls $(2 \mathrm{~T}+2 \mathrm{~B})$ which shows almost a negligible change. $\mathrm{Nu}$ continues to walls $(2 \mathrm{R})$ or total of four fins with pairs at the left and right walls $(2 \mathrm{~L}+2 \mathrm{R})$, whereas it increases for the

4

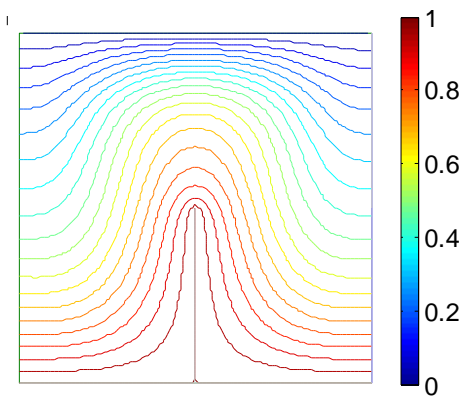

orientations except total of four fins with pairs for two fins placed at the left (2L) or righ 


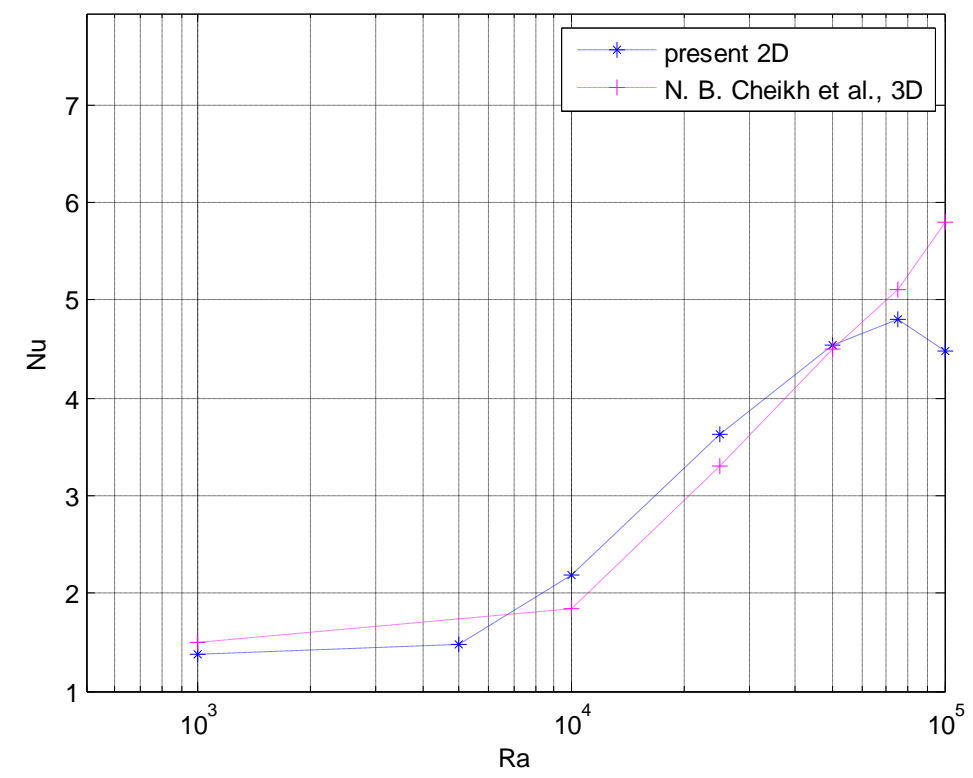

Fig. 4 Nu vs. Ra in an enclosure with a fin located at the bottom hot surface.

configurations of $2 \mathrm{~T}, 2 \mathrm{~B}$, and $2 \mathrm{~T}+2 \mathrm{~B}$ for $l_{f}=0.35$. Among all six cases, the most reduction in heat transfer occurs when a pair of fins is located at each of insulated left and right walls.

Flow and temperature fields are shown in terms of streamlines and isotherms in Fig. 7 for the arrangements described above. When two fins are placed at the bottom wall (2B), there is one main cell rotating clockwise with additional smaller cells in the finned area for $l_{f}=0.1$ and 0.2 . Transition to two-cell structure rotating opposite to each other occurs for $l_{f}=$ 0.25 . Similar two counter-rotating cells are formed for $l_{f}=0.35$. Predicted single- or two-cell flow fields are at a sufficient strength to affect the temperature fields which are shown at the next row suggesting that convection heat transfer is the dominant regime compared to conduction. Mushroom profile of isotherms is observed when $l_{f}=0.25$ and 0.35 as a result of two counter-rotating rolls. When two fins are located at the top wall (2T), one main cell is persistent for all fin lengths with additional small cells appearing in the finned area. Isotherms in the next row show distortion again as a result of the convection dominated heat transfer. When two fins are placed at the insulated left (2L) or right wall (skipped because of similarity), there is again one main roll with additional small rolls in the finned area. Isotherms are squeezed less at the bottom for $l_{f}=0.35$, indicating reduced heat transfer which was discussed in connection with Fig. 6. Increasing the total number of fins to four at the bottom and top walls $(2 \mathrm{~T}+2 \mathrm{~B})$ results in two cells side by side rotationg opposite to each other for $l_{f}=0.1$. As a result, corresponding isotherms show mushroom-like distribution. For $l_{f}=$ 0.2 and 0.25 , one main cell appears with additional four smaller vortices in the finned area. When $l_{f}=0.35$, one main cell is present in the middle with additional six smaller cells around it. Moving the two pairs of fins to insulated walls $(2 \mathrm{~L}+2 \mathrm{R})$ yields one persistent main cell for all fin lengths; its strength, however, decreases with fin length, consistent with Fig. 6. Two or four weak vortices accompany the main single cell.

\subsubsection{Fins Located Evenly, $s=[0.33,0.67]$}

When fins are spaced evenly $(s=[0.33,0.67])$ as opposed to $s=[0.23,0.77]$ of the preceding section, reduction in $\mathrm{Nu}$ is also observed for all fin arrangements. However, not all cases lead to a steady solution anymore. Illustrating the history of $\mathrm{Nu}$, Fig. 8 now suggests that the behavior of system is quite different with each fin arrangement for the onset of 
convective instability. Short fin length, $l_{f}=0.1$ of Fig. $8 \mathrm{a}$ results in a steady solution except for the case of $2 \mathrm{~L}+2 \mathrm{R}$. In the case of $2 \mathrm{~L}$ ( or $2 \mathrm{R}$ ), longer fins show regular sinusoidal oscillating behavior. The case of $2 \mathrm{~L}$ $+2 \mathrm{R}$ shows unsteadiness with less frequent oscillations compared to a pair of fins either at the left (2L) or right (2R) wall for $l_{f}=0.2$ (Fig. 8b) and 0.25
(Fig. 8c) and it becomes nearly steady for $l_{f}=0.35$ (Fig. 8d). Smallest mean value of heat transfer is obtained with $2 \mathrm{~L}+2 \mathrm{R}$.

Flow and temperature fields are shown in terms of streamlines and isotherms in Fig. 9 for the orientations described above. When two fins are placed at the bottom wall $(2 \mathrm{~B})$, there is only one main cell rotating

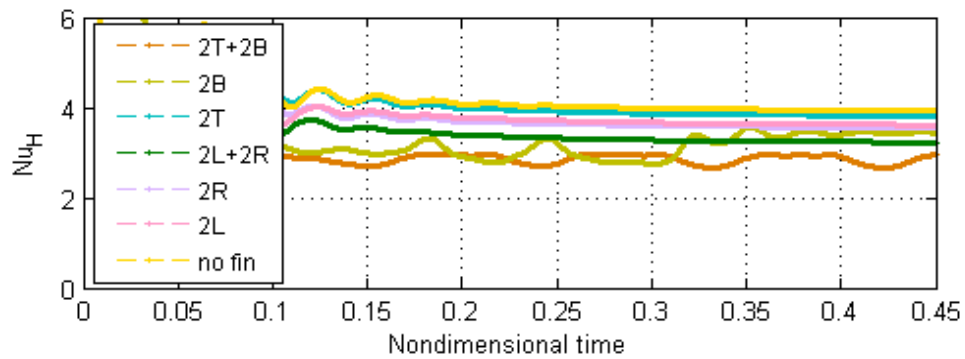

(a)

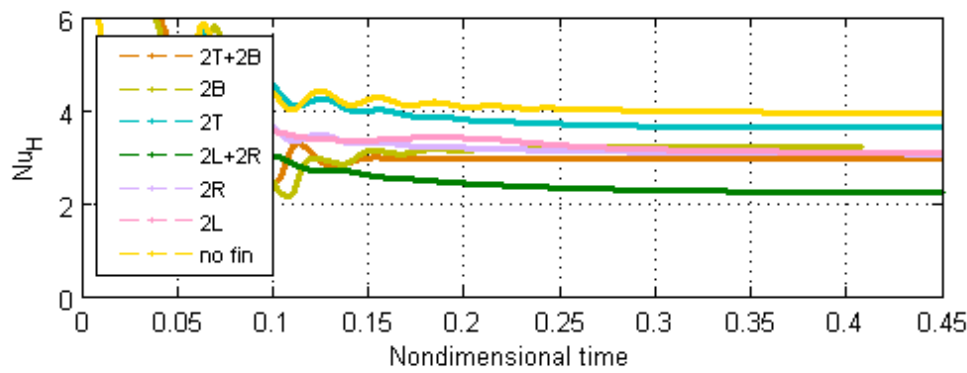

(b)

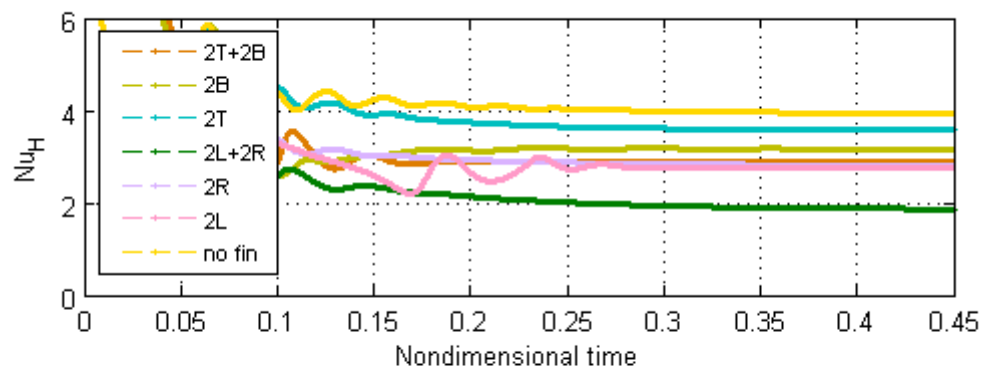

(c)

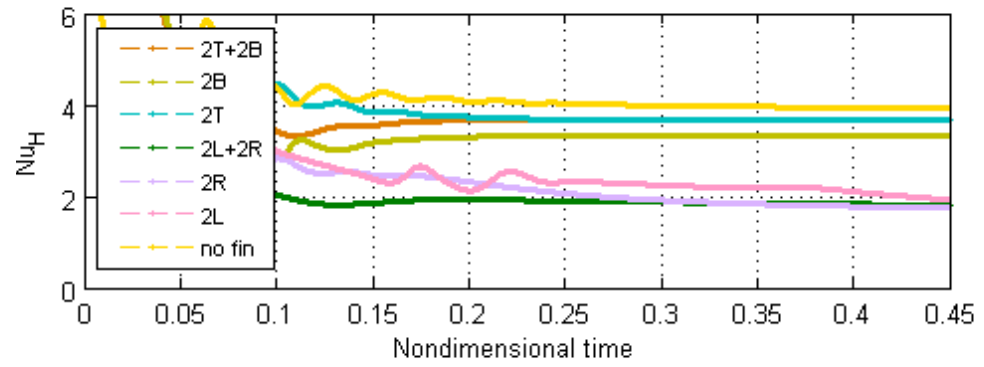

(d)

Fig. 5 Evolution of $\mathrm{Nu}$ for $\mathrm{Ra}=10^{5}$ with different fin arrangements and for (a) $l_{f}=0.1$, (b) $0.2,(\mathrm{c}) 0.25$, and (d) $0.35 ; s=[0.23$, 0.77]. 


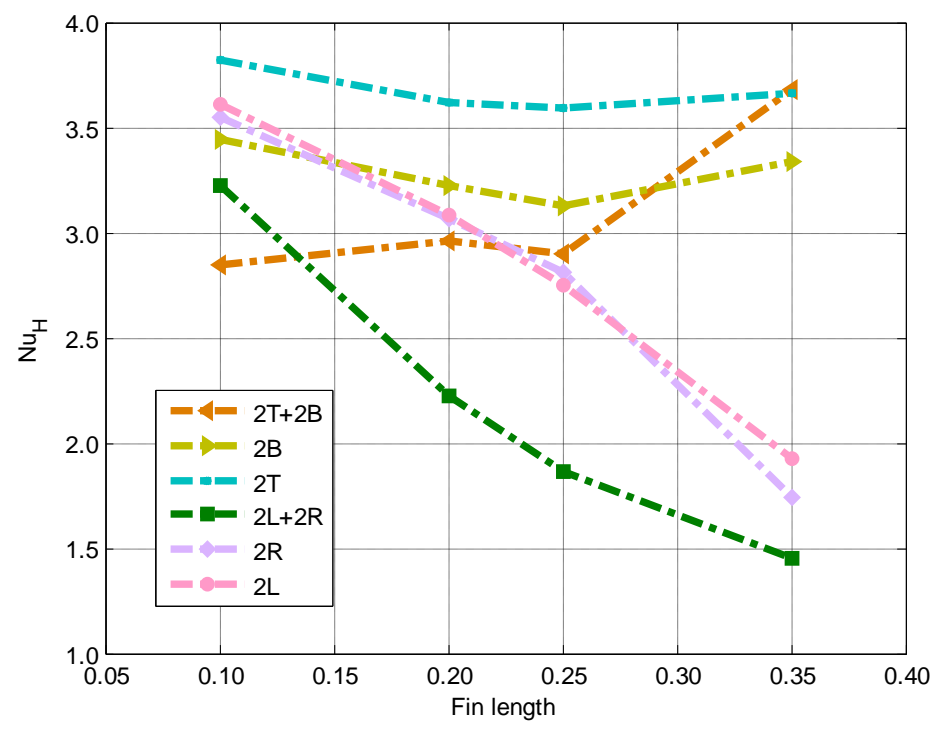

Fig. 6 Nu vs. fin length with different fin arrangements for $s=[0.23,0.77]$ and $R a=10^{5}$.

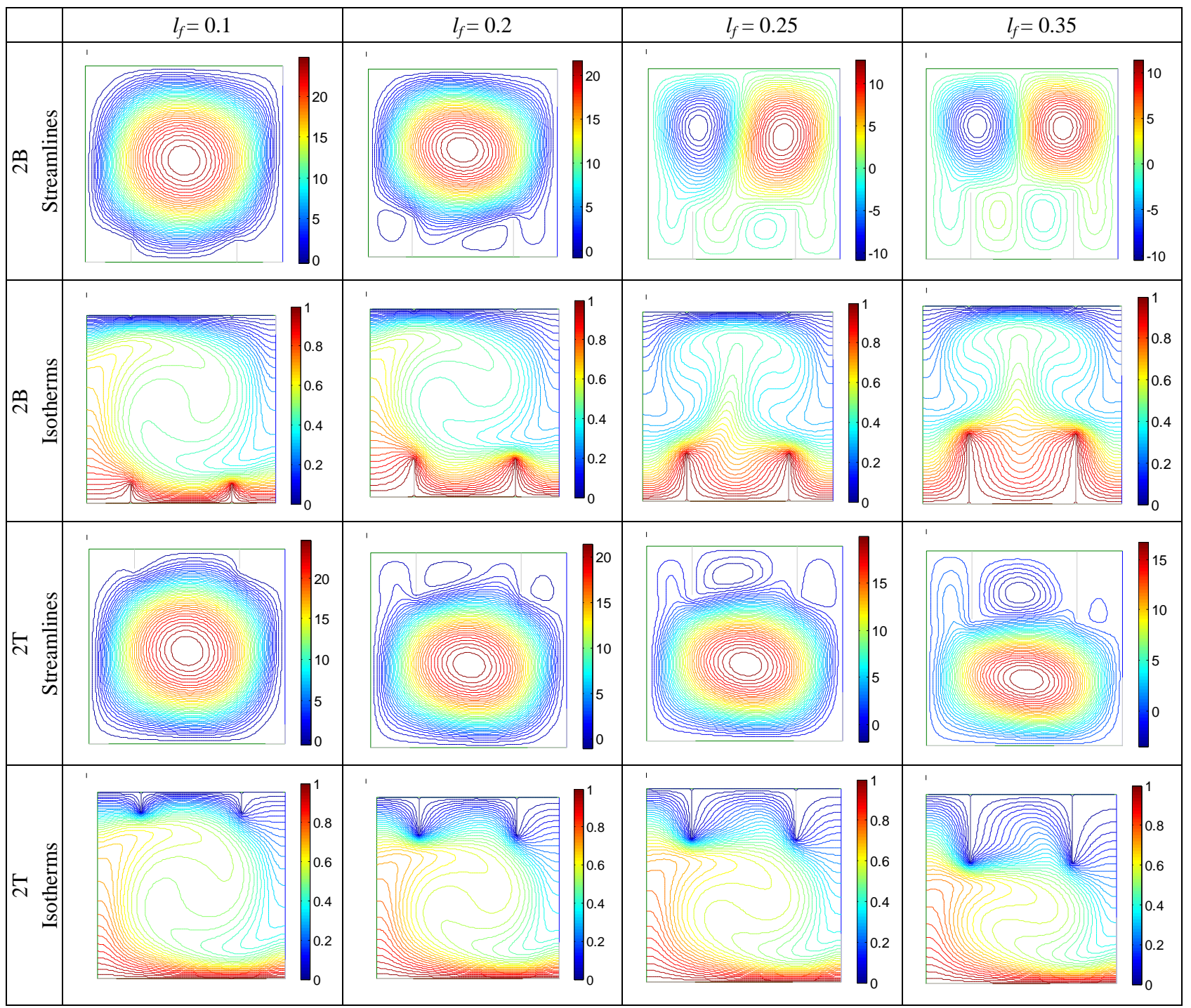




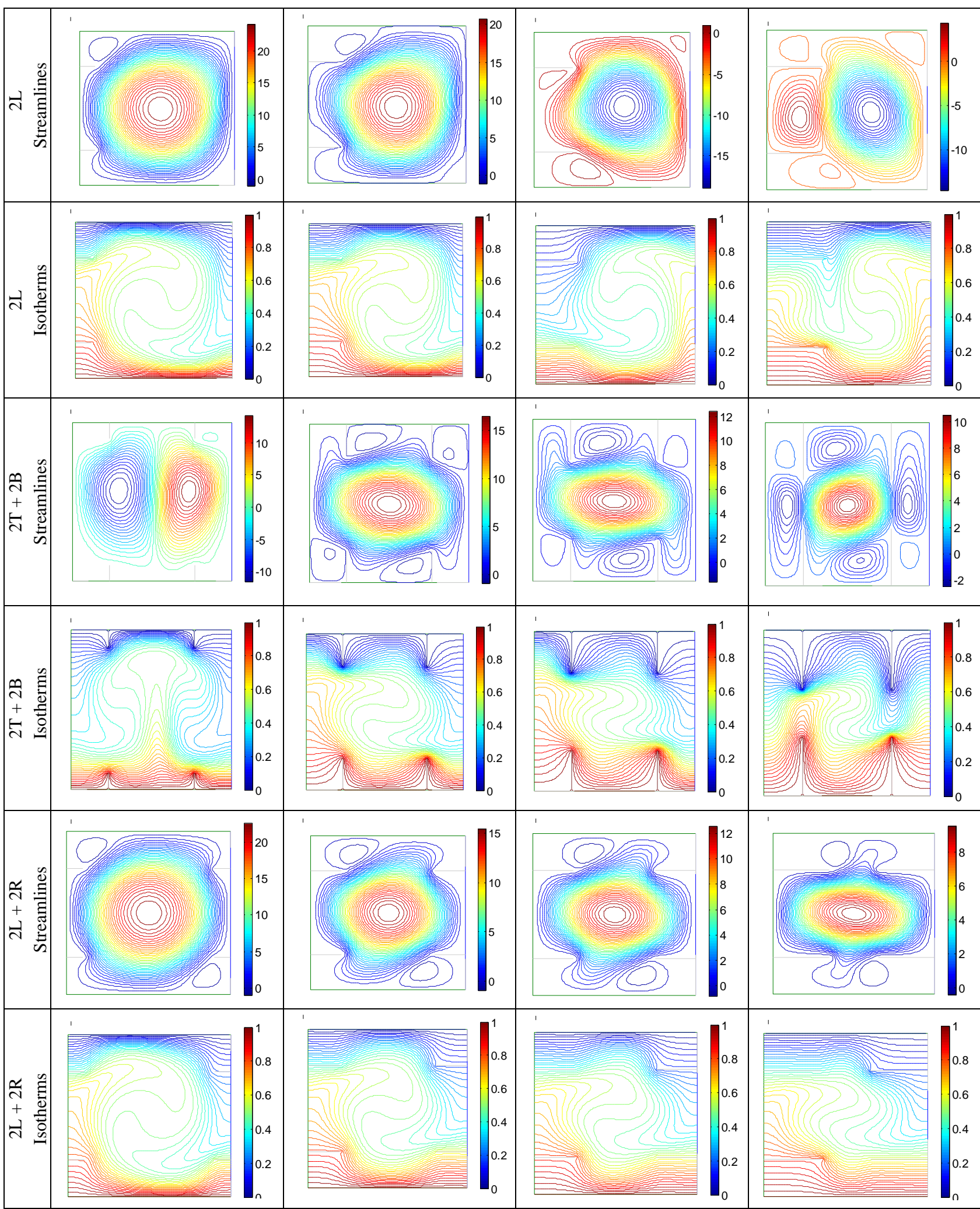

Fig. 7 Streamlines (first row in each pair) and isotherms (next row in each pair) with different fin arrangements for $l_{f}=0.1$, $0.2,0.25$, and $0.35 ; s=[0.23,0.77]$ at $\mathrm{Ra}=10^{5}$. 


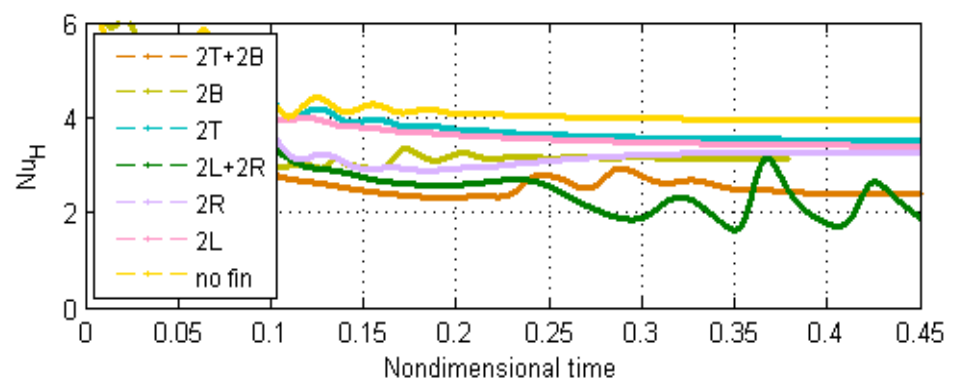

(a)

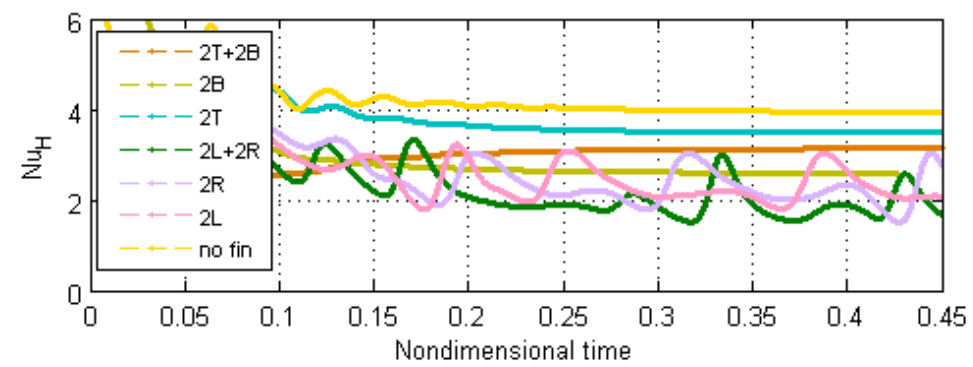

(b)

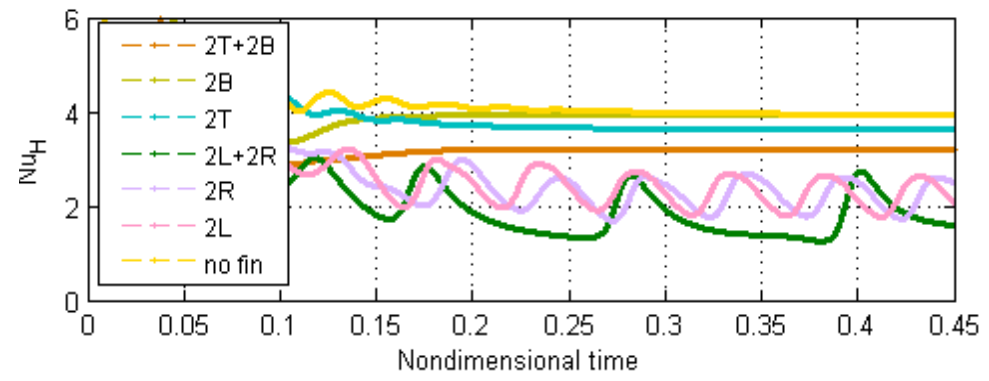

(c)

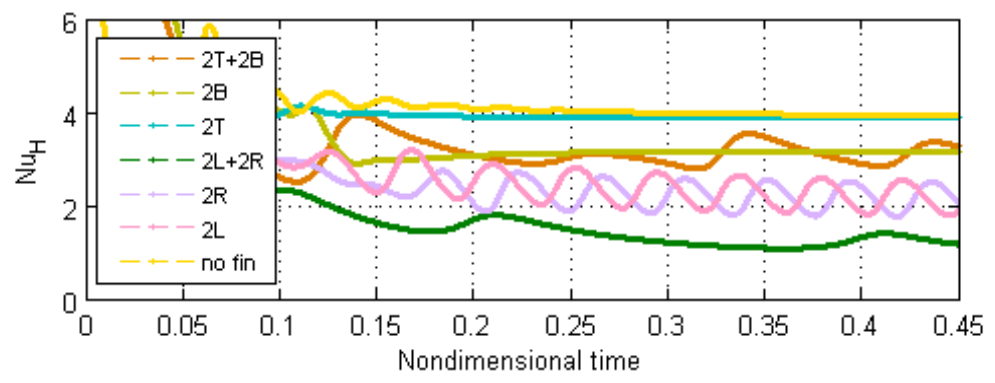

(d)

Fig. 8 Evolution of Nu for $\mathrm{Ra}=10^{5}$ with different fin arrangements for (a) $l_{f}=0.1$, (b) $l_{f}=0.2,(\mathrm{c}) l_{f}=0.25$, (d) $l_{f}=0.35 ; s=$ $[0.33,0.67]$.

clockwise for $l_{f}=0.1$. Transition to two-cell structure occurs for $l_{f}=0.2$ (as opposed to 0.25 for earlier $s=$ $[0.23,0.77])$. Mushroom profiles of isotherms are apparent in the next row for $l_{f}=0.2,0.25$, and 0.35 . When two fins are positioned at the top wall (2T), one main cell is persistent (though decreasing in strength with length) with additional two small cells appearing in the finned area. Isotherms show distortion accordingly in the next row. When two fins are at the insulated left wall $(2 \mathrm{~L})$, there is one main cell for $l_{f}=$ 0.1 with an additional small cell in top left corner. Transition to two cells rotating in opposite directions 


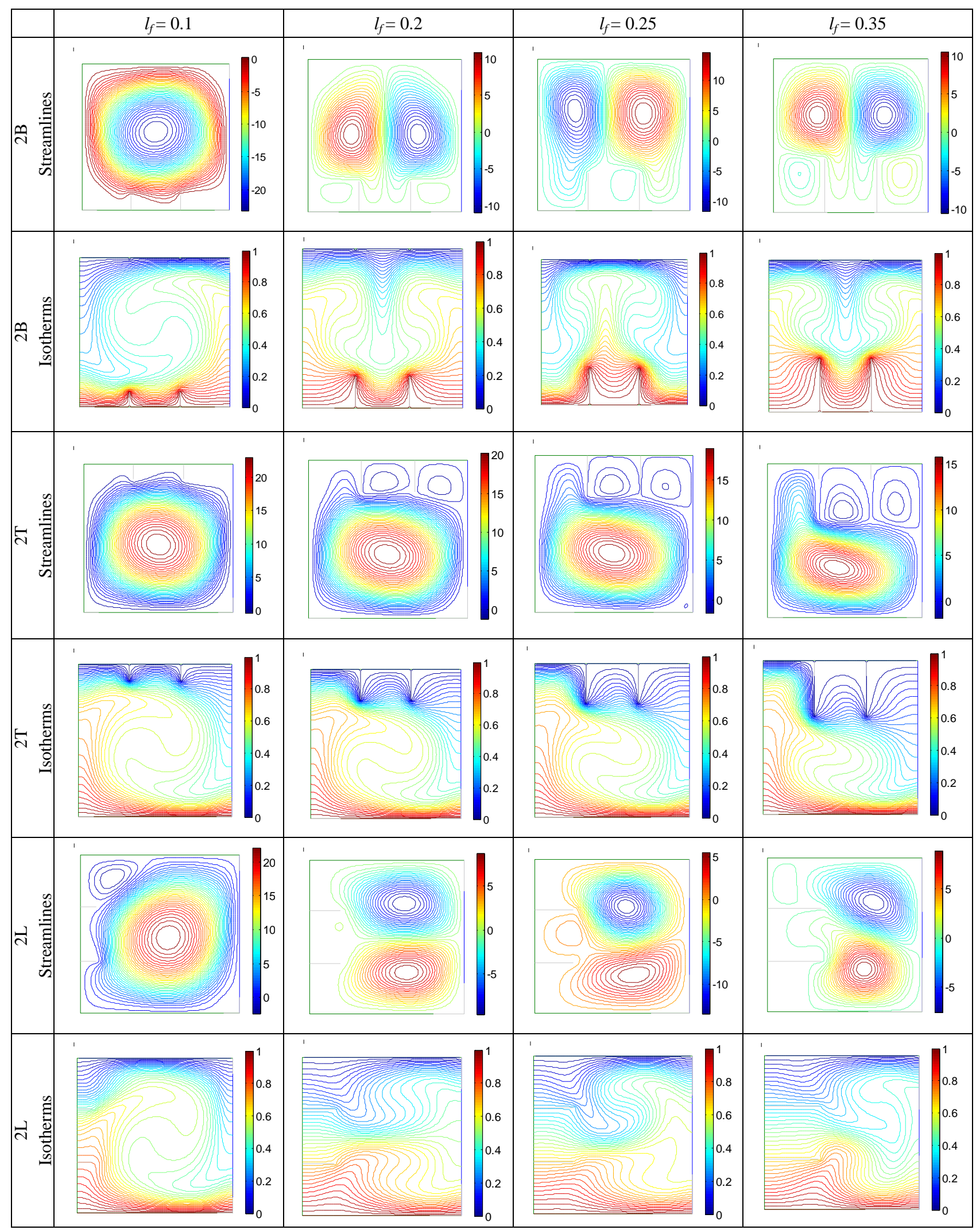




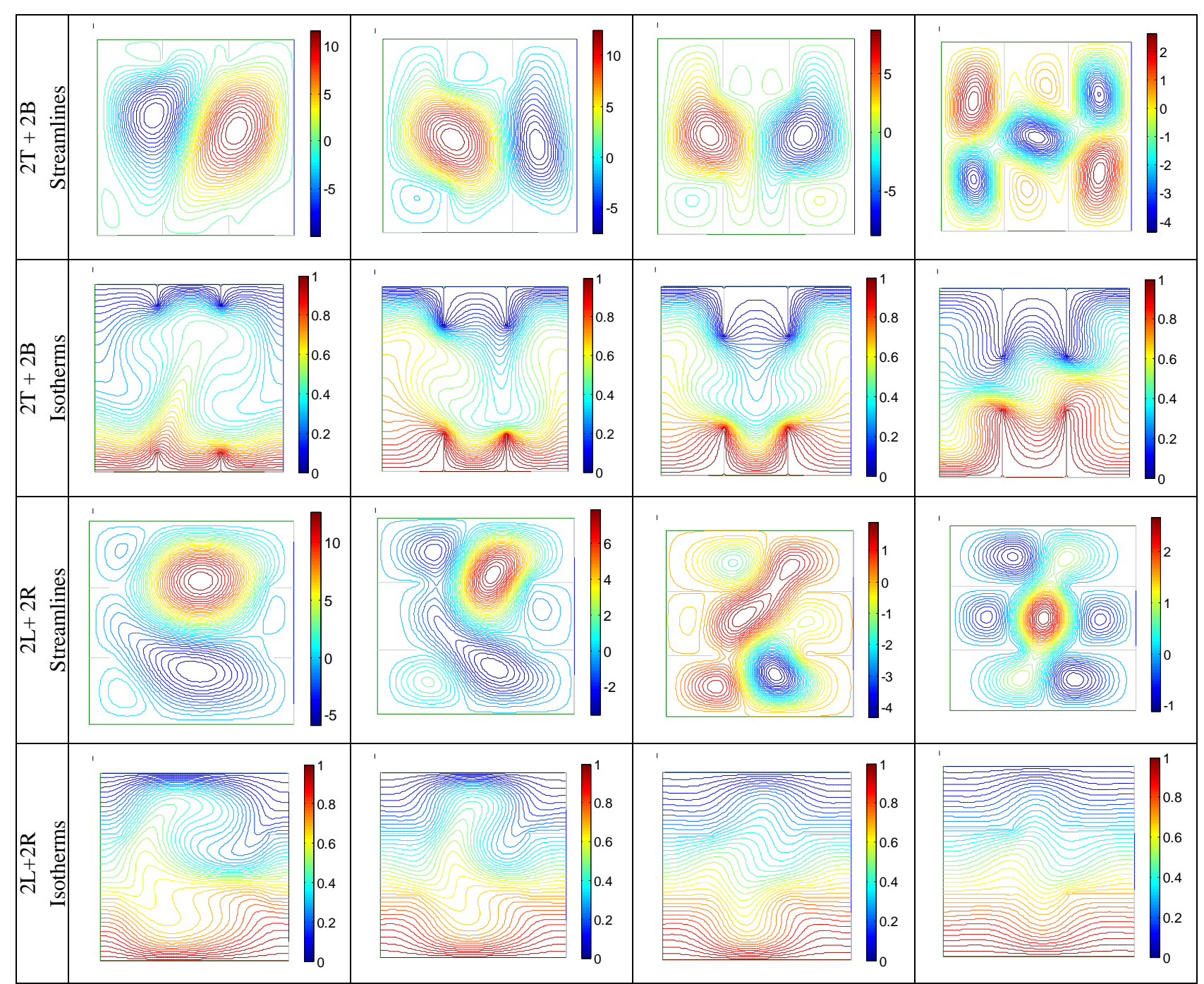

Fig. 9 Streamlines (first row in each pair) and isotherms (next row in each pair) for $l_{f}=0.1,0.2,0.25$, and 0.35 , with different fin arrangements of $s=[0.33,0.67]$ at $\mathrm{Ra}=10^{5}$.

takes place for $l_{f}=0.2$ similar to the case of $2 \mathrm{~B}$ except the cells here are on top of each other (instead of side by side), with additional small ones appearing in the finned area. Corresponding isotherms show reduced heat transfer with transition to two-cell structure. Results of $2 \mathrm{R}$ are skipped since they are similar to those of $2 \mathrm{~L}$. Switching the fin orientation to $2 \mathrm{~T}+2 \mathrm{~B}$ produces two cells side by side and rotating opposite to each other for $l_{f}=0.1$. For $l_{f}=0.2$ and 0.25 , two cells persist but change in shape. When the fin length is further increased to 0.35 , the total number of cells becomes seven, three in the middle and two at both sides on top of each other, all rotating opposite to each other. Moving the two pairs of fins to insulated walls
$(2 \mathrm{~L}+2 \mathrm{R})$ causes oscillatory (recall Fig. 8) convection for $l_{f}=0.1,0.2$, and 0.25 . For $l_{f}=0.1$, there are two cells on top of each other with additional two or three small ones. Multiple cells are present changing from five to seven with different shapes and strength for $l_{f}=$ 0.2 and 0.25 , and steady seven cells for $l_{f}=0.35$. The corresponding isotherms are least crowded near hot wall among six fin arrangements, consistent with Fig. 8.

4.2 Results for $R a=5 \times 10^{5}$

A higher Ra is considered next to examine its effect on the results with the same fin arrangements.

4.2.1 Fins Located Unevenly, $s=[0.23,0.77]$

Fig. 10 shows the evolution of $\mathrm{Nu}$ for fins of (a) 


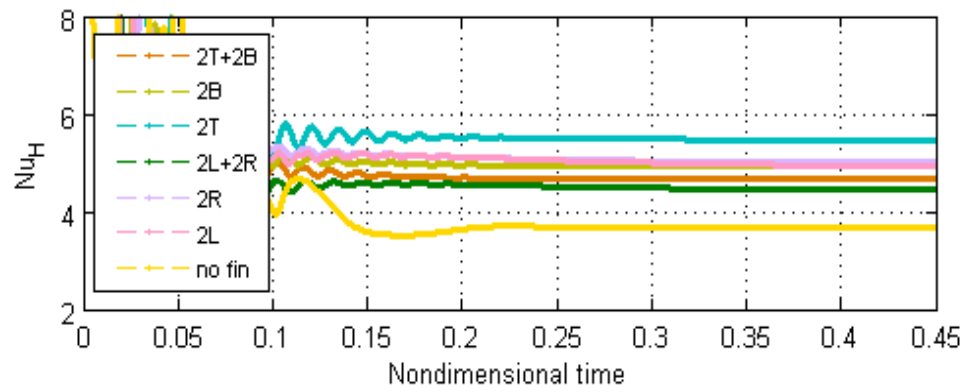

(a)

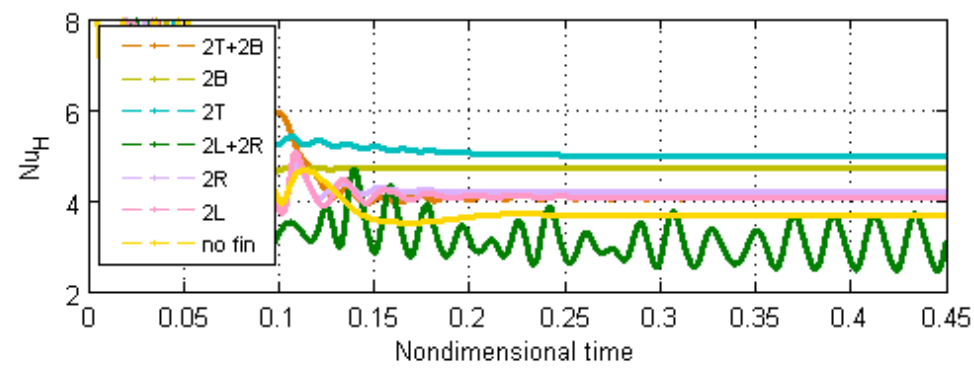

(b)

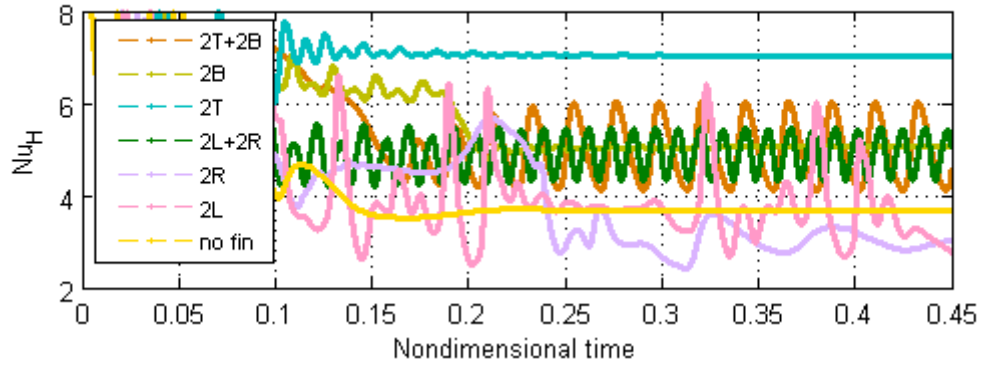

(c)

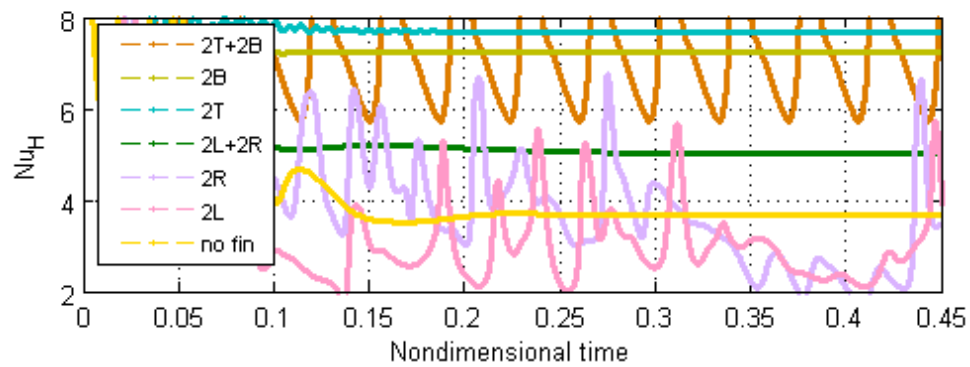

(d)

Fig. 10 Evolution of $\mathrm{Nu}$ for $\mathrm{Ra}=5 \times 10^{5}$ with different fin arrangements for (a) $l_{f}=0.1$, (b) $l_{f}=0.2$, (c) $l_{f}=0.25$, and (d) $l_{f}=$ $0.35 ; s=[0.23,0.77]$.

$l_{f}=0.1$, (b) $l_{f}=0.2$, (c) $l_{f}=0.25$, and (d) $l_{f}=0.35$ with $s$ $=[0.23,0.77]$ and six different cases including no-fin baseline at $\mathrm{Ra}=5 \times 10^{5}$. Steady state is present for all the fin arrangements when $l_{f}=0.1$, and interestingly $\mathrm{Nu}$ is larger than no-fin case in contrast to $\mathrm{Ra}=10^{5}$ of Fig. 5a. $\mathrm{Nu}$ reaches steady state also when $l_{f}=0.2$ for all cases except for $2 \mathrm{~L}+2 \mathrm{R}$ which exhibits sinusoidal oscillations with amplitudes smaller than that of no-fin case. This behavior also deviates from that of Fig. $5 b$ for $\mathrm{Ra}=10^{5}$. For $l_{f}=0.25$, steady state is reached only when two fins are placed at the top wall $(2 \mathrm{~T})$, while also yielding the largest $\mathrm{Nu}$. When two fins are at the bottom (2B), $\mathrm{Nu}$ decreases considerably while remaining still larger than that of the baseline. The fin 
placements of $2 \mathrm{~T}+2 \mathrm{~B}$ and $2 \mathrm{~L}+2 \mathrm{R}$ both result in sinusoidal oscillations, though differing in amplitude and frequency. The cases of $2 \mathrm{~L}$ and $2 \mathrm{R}$, on the other hand, manifest rather erratic behavior with heat transfer fluctuating near the no-fin case. With a longer fin length of $l_{f}=0.35$, steady state is reached for placements of $2 \mathrm{~B}, 2 \mathrm{~T}$, and $2 \mathrm{~L}+2 \mathrm{R}$, whereas $2 \mathrm{~T}+2 \mathrm{~B}$ promotes a rather large periodic variation. Even though $\mathrm{Nu}$ shows quite an irregular evolution for $2 \mathrm{~L}$ and $2 \mathrm{R}$, it interestingly reaches a steady state for $2 \mathrm{~L}+$ $2 \mathrm{R}$. $\mathrm{Nu}$ is largest for $2 \mathrm{~T}$, followed by $2 \mathrm{~B}, 2 \mathrm{~T}+2 \mathrm{~B}$ (on the mean), and $2 L+2 R$. Placing fins only on the left $(2 \mathrm{~L})$ or right wall $(2 \mathrm{R})$ may not be desirable for $l_{f}=$ 0.25 or 0.35 since both bring chaotic behavior.

In summary, comparison of Figs. 5 and 10 reveals that the results with two different $\mathrm{Ra}$ are quite different in terms of magnitude and behavior of $\mathrm{Nu}$ with the same fin arrangements. Fins with the exception of $2 \mathrm{~L}$ and $2 \mathrm{R}$ cause enhancement of heat transfer at $\mathrm{Ra}=5 \times 10^{5}$, they cause suppression at $\mathrm{Ra}$ $=10^{5}$.

Fig. 11 shows the streamlines and isotherms for $\mathrm{Ra}$ $=5 \times 10^{5}, s=[0.23,0.77]$ with the six different arrangements at four different fin lengths. For the 2B configuration, flow fields are similar to $\mathrm{Ra}=10^{5}$ but with increased strength except for $l_{f}=0.25$ which maintains the single cell flow as opposed to the transition to two-cell structure earlier. In comparison with Fig. 7, isotherms now illustrate the effect of increased strength of convection. The top orientation

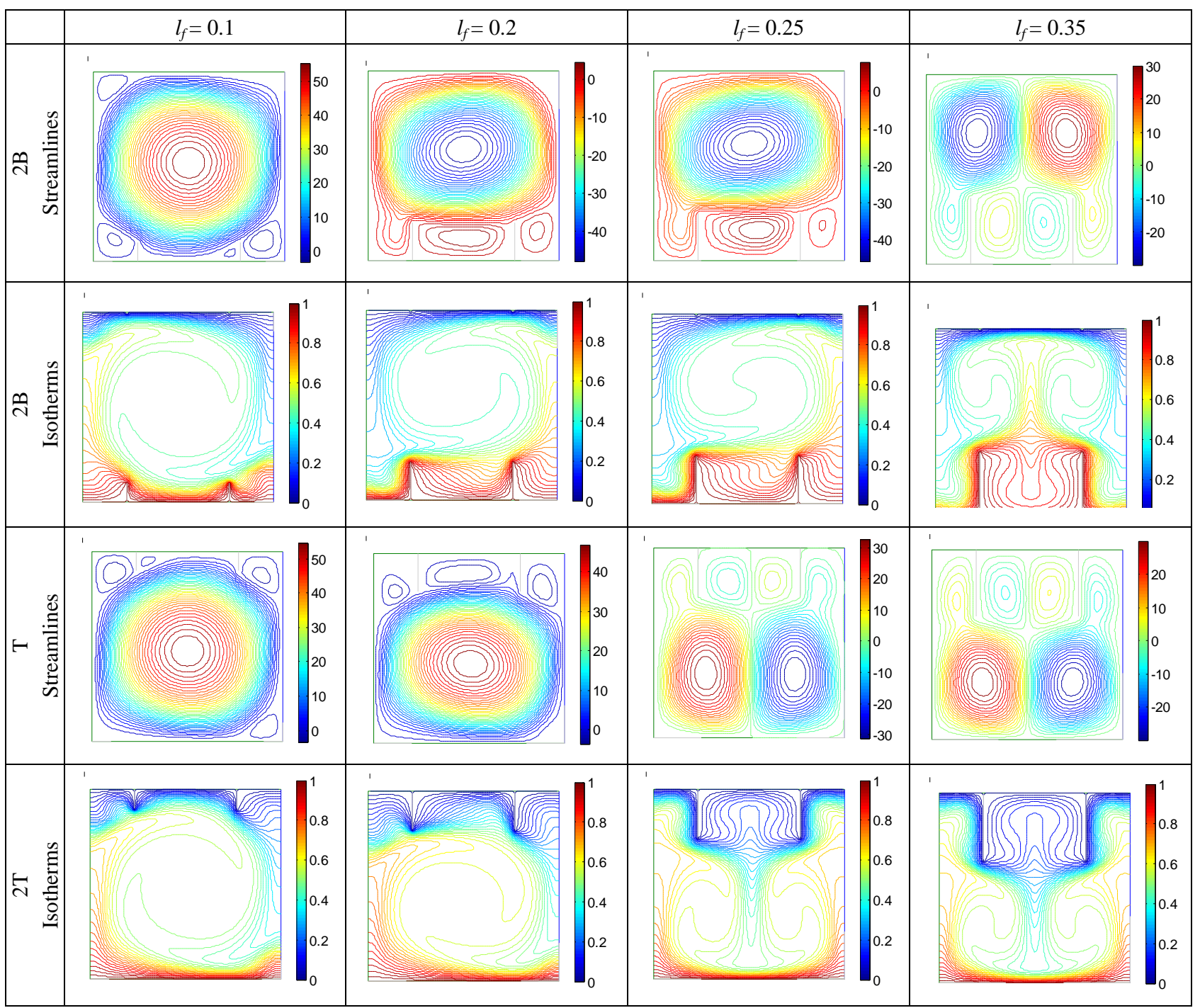




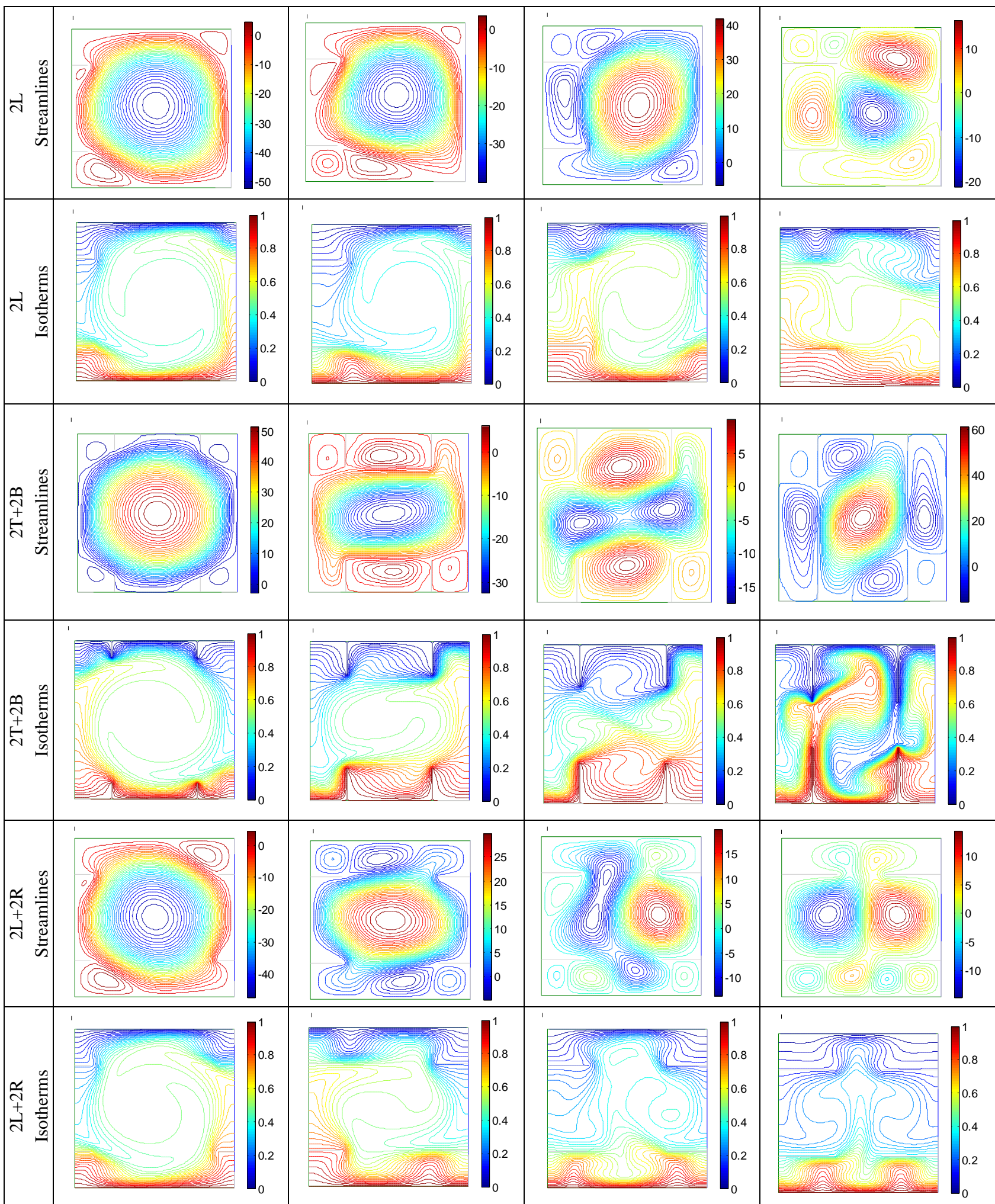

Fig. 11 Streamlines (first row in each pair) and isotherms (next row in each pair) with different fin arrangements for $l_{f}=0.1$, $0.2,0.25$, and $0.35 ; s=[0.23,0.77]$ at $\mathrm{Ra}=5 \times 10^{5}$. 
(2T) transitions to two cells - side by side and rotating opposite to each other-with additional four smaller ones in the finned area for $l_{f}=0.25$, whereas such a transition did not happen for $\mathrm{Ra}=10^{5}$ for all fin lengths, (refer to Fig. 7). The 2L placement produces one main cell rotating anti-clockwise along with other smaller cells. For $l_{f}=0.25$, the direction of rotating main cell changes to clockwise. Increasing the fin length to $l_{f}=0.35$ leads to a multi-cell structure (up to seven unstable cells). For $2 \mathrm{~T}+2 \mathrm{~B}$, the single-cell structure appears for $l_{f}=0.1$ as opposed to earlier side by side two cells for $\mathrm{Ra}=10^{5}$. For $l_{f}=0.2$, the main cell is distorted with additional smaller cells appearing in the finned section. Increasing the fin length to $l_{f}=$ 0.25 and 0.35 results in a multi-cell, six and seven cell structures, respectively. Flow and temperature fields shown, for example, at the instance of $t=0.45$ change with time for $l_{f}=0.25$ and 0.35 because of the unsteadiness. Finally, the placement of $2 L+2 R$ generates one main cell accompanied by two and four smaller cells for $l_{f}=0.1$ and 0.2 , respectively. Increasing the fin length to $l_{f}=0.25$ introduces unsteadiness (recall Fig. 10c) up to nine cells. Further increase to $l_{f}=0.35$ has a stabilizing effect, now with two side by side cells in the middle, two smaller ones on top, and four smaller ones at the bottom adding up to an eight-cell structure, in contrast to one main cell and two weak bottom ones for $\mathrm{Ra}=10^{5}$.

\subsubsection{Fins Located Evenly, $s=[0.33,0.67]$}

In this final section, fins are located evenly ( $s=$ $[0.33,0.67])$ similar to Section 4.1 .2 which was for $\mathrm{Ra}$ $=10^{5}$. Fig. 12 shows the corresponding evolution of $\mathrm{Nu}$ for six different arrangements and four different fin lengths. For $l_{f}=0.1$ (Fig. 12a), placing fins at the top wall (2T) again produces the maximum steady $\mathrm{Nu}$, followed by $2 \mathrm{~B}$, with both cases increasing the heat transfer relative to the no-fin case. For $2 \mathrm{~T}+2 \mathrm{~B}, \mathrm{Nu}$ is nearly the same as no-fin case. Locating two fins at the left (2L) or right wall (2R) causes slightly irregular periodic behavior, whereas total of four fins with pairs at both left and right walls $(2 \mathrm{~L}+2 \mathrm{R})$ generate irregular non-periodic Nu. Recalling from Fig. 10a for $l_{f}=0.1$, note that the results for unevenly distributed fins $(s=[0.23,0.77])$ were steady for all arrangements. For $l_{f}=0.2$ (Fig. 12b), 2T placement again gives the maximum steady $\mathrm{Nu}$, followed by $2 \mathrm{~B}$, with both increasing the heat transfer relative to the no-fin case. With both $2 \mathrm{~L}$ and $2 \mathrm{R}$ orientations, $\mathrm{Nu}$ is slightly higher than that of the baseline and exhibits regular oscillatory behavior, in contrast to earlier steady results for $s=[0.23,0.77]$. For $2 \mathrm{~T}+2 \mathrm{~B}, \mathrm{Nu}$ is steady and the same as no-fin case. The placement $2 \mathrm{~L}+2 \mathrm{R}$ now creates a chaotic behavior which is used to be mere periodic oscillations for $s=\left[\begin{array}{ll}0.23,0.77\end{array}\right]$. Increasing $l_{f}$ to 0.25 (Fig. 12c) yields similar results. The configurations of $2 \mathrm{~L}$ and $2 \mathrm{R}$ produce periodic oscillations for even spacing, whereas they showed irregular oscillations earlier for uneven spacing. This trend is reversed in the comparison of $2 \mathrm{~L}+2 \mathrm{R}$ with even spacing versus uneven spacing. While further increase in fin length to 0.35 (Fig. 12d) leads to a chaotic behavior for $2 \mathrm{~T}+2 \mathrm{~B}$, a steady solution for $2 \mathrm{~L}$ $+2 \mathrm{R}$, and regular sinusoidal oscillations for the remaining cases. Interestingly, fins at the left wall (2L) decrease the heat transfer relative to no-fin case, contrary to 2R. Comparison of Figs. 10 and 12 reveals that $\mathrm{Nu}$ variation can be dramatically different in terms of its magnitude and frequency with two different spacing: depending on the fin length, even spacing of fins may lead to more or less stability relative to the uneven spacing.

Fig. 13 shows streamlines and isotherms for $s=$ $[0.33,0.67]$. Results for $2 \mathrm{~B}$ are similar to those of earlier $s=[0.23,0.67]$. With $2 \mathrm{~T}$, the transition to two side by side cells occurs at $l_{f}=0.35$, as opposed to $l_{f}=$ 0.25 of $s=[0.23,0.67]$. With $2 \mathrm{~L}$, there are two cells on top of each other rotating in opposite directions for $l_{f}=0.1,0.2,0.25$, as opposed to a single cell of $s=$ $[0.23,0.77]$. For $l_{f}=0.35$, periodic three-cell structure appears, in contrast to up to six cells of uneven spacing. With $2 \mathrm{~T}+2 \mathrm{~B}$, a single main cell is observed along with additional smaller ones for $l_{f}=0.1$ and 0.2 ; 
longer fin lengths produce up to eight or nine unstable cell structures, as opposed to six to seven for uneven spacing. For $2 \mathrm{~L}+2 \mathrm{R}$, unsteady five-cell structure exists for $l_{f}=0.1$, seven cells appear for $l_{f}=0.2$ and
0.25 , and steady flow field is established for $l_{f}=0.35$ with one cell in the middle joined by three on top and another three at the bottom; all being entirely different from those of earlier $s=[0.23,0.77]$.

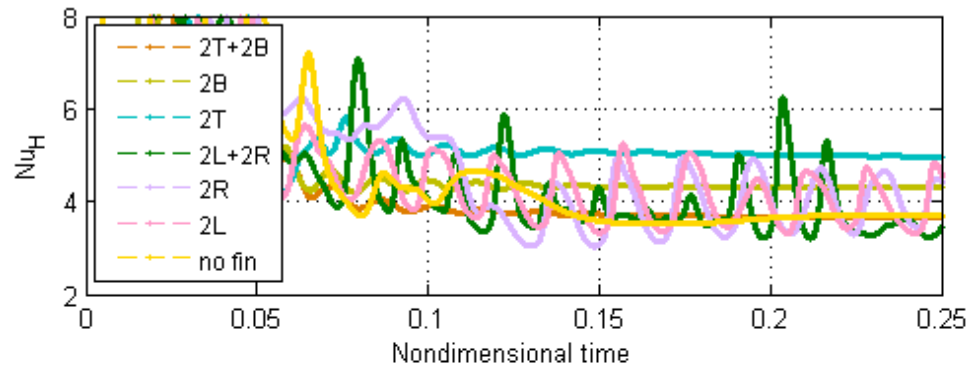

(a)

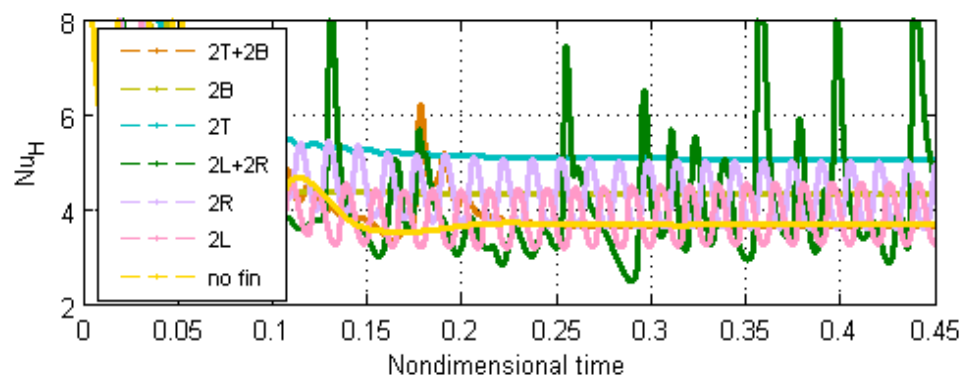

(b)

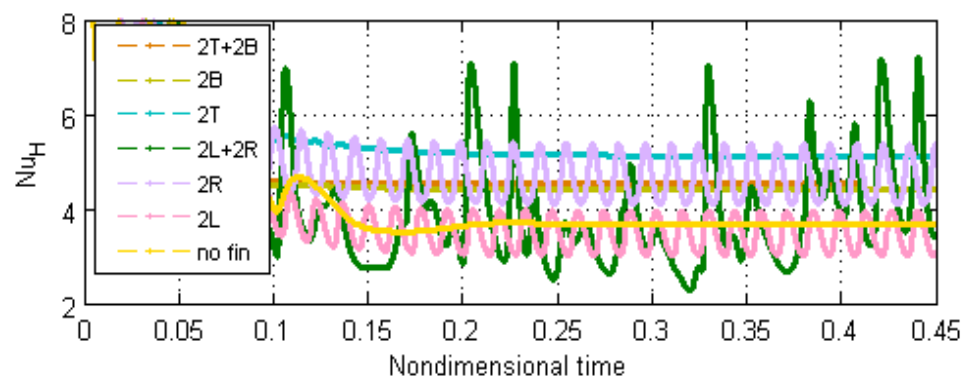

(c)

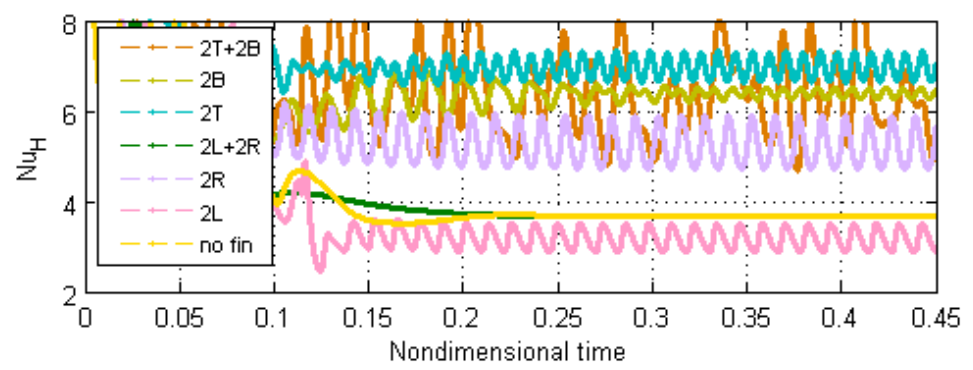

(d)

Fig. 12 Evolution of Nu with different fin arrangements for (a) $l_{f}=0.1$, (b) $l_{f}=0.2$, (c) $l_{f}=0.25$, and (d) $l_{f}=0.35 ; s=[0.33$, $0.67]$ at $\operatorname{Ra}=5 \times 10^{5}$. 


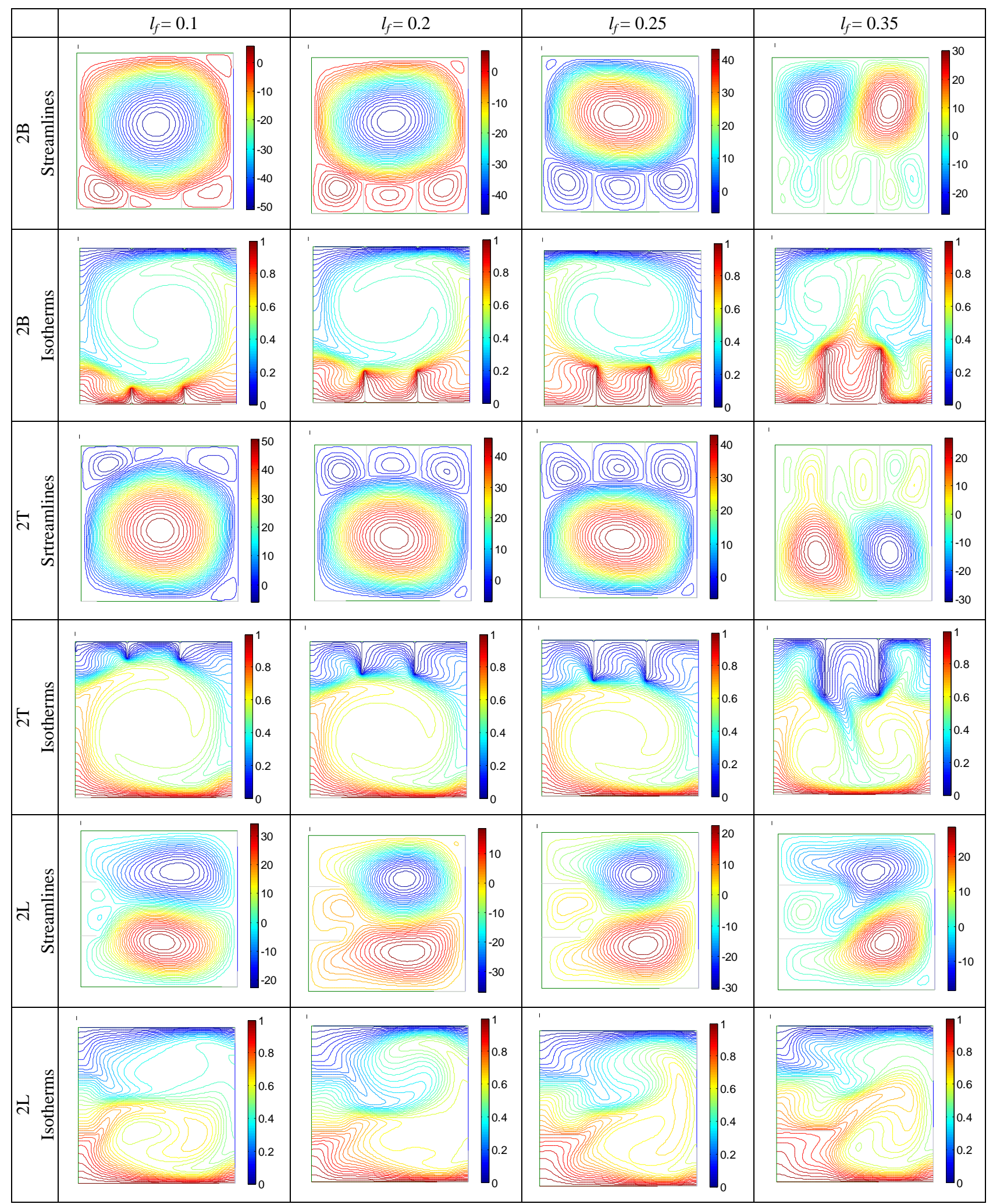






Fig. 13 Streamlines (first row in each pair) and isotherms (next row in each pair) with different fin arrangements for $l_{f}=0.1$, $0.2,0.25$, and $0.35 ; s=[0.33,0.67]$ at $\mathrm{Ra}=5 \times 10^{5}$.

\section{Concluding Remarks}

Careful evaluation of transition to unsteady convection is particularly critical in the study of Rayleigh-Benard problem. Unsteady governing equations are solved in the present work numerically due to the importance of development history of flow instabilities and the inherent temporal behavior in a variety of cases. Relevant calculations have been performed to examine the behavior of the system with different fin arrangements and lengths. The development of the flow field over time for different conditions and cases and its effect on isotherms are demonstrated. The results indicate that the spacing and the length of fins can cause transition from steady state to an oscillatory regime with different amplitude and frequencies. The effect of fin lengths and spacing has to be investigated to achieve the desired results for different $\mathrm{Ra}$ since heat transfer reduction or augmentation may occur compared to the no-fin case.

\section{References}

[1] George, V. 1966. "Large-Amplitude Benard Convection." Journal of Fluid Mechanics 26 (1): 49-68.

[2] Schneck, P., and Veronis, G. 1967. "Comparison of Some Experimental and Numerical Results in Benard Convection." Physics of Fluids 10 (5): 927-31.

[3] Catton, I. 1972. "The Effect of Insulating Vertical Walls on the Onset of Motion in a Fluid Heated from Below." 
International Journal of Heat and Mass Transfer 15 (4): 665-72.

[4] Moore, D. R., and Weiss, N. O. 1973. "Two-Dimensional Rayleigh-Benard Convection.” Journal of Fluid Mechanics 58 (2): 289-312.

[5] Busse, F. H., and Clever, R. M. 1979. "Instabilities of Convection Rolls in a Fluid of Moderate Prandtl Number." Journal of Fluid Mechanics 91 (2): 319-35.

[6] Kolodner, P., Walden, R. W., Passner, A., and Surko, C. M. 1986. "Rayleigh-Benard Convection in an Intermediate Aspect Ratio Rectangular Container." Journal of Fluid Mechanics 163 (February): 195-226.

[7] Mukutmoni, D., and Yang, K. T. 1993. "Rayleigh-Benard Convection in a Small Aspect Ratio Enclosure: Part II-Bifurcation to Chaos." Journal of Heat Transfer 115 (2): $367-76$

[8] Watanabe, T., Kaburaki, H., and Yokokawa, M. 1993. "Simulation of Two-dimensional Rayleigh-Benard System Using the Direct Simulation." Physical Review E 49 (5): 4060-4.

[9] Gelfgat, A. Y. 1999. "Different Modes of Rayleigh-Benard Instability in Two- and Three-Dimensional Rectangular Enclosures." Journal of Computational Physics 156 (2): 300-24.

[10] Pallares, J., Grau, F. X., and Giralt, F. 1999. "Flow Transitions in Laminar Rayleigh-Benard Convection in a Cubical Cavity at Moderate Rayleigh Numbers." International Journal of Heat and Mass Transfer 42 (4): 753-69.

[11] Stella, F., and Bucchignani, E. 1999. "Rayleigh-Benard Convection in Limited Domains: Part 1-Oscillatory Flow." Numerical Heat Transfer, Part A 36 (1): 1-16.

[12] Ourtatani, N., Ben-Cheikh, N., Brahim, B. B., and Taieb, L. 2017. "Numerical Simulation of Two-Dimensional Rayleigh-Benard Convection in Enclosure." Comptes Rendus Mécanique 336 (5): 464-70.

[13] van der Poel, E. P., Stevens, R. J. A. M., and Lohse, D. 2013. "Comparison between Two- and Three-Dimensional Rayleigh-Benard Convection." Journal of Fluid Mechanics 736 (December): 177-94.

[14] Stevens, R. J. A. M., Lohse, D., and Verzicco, R. 2014. "Sidewall Effects in Rayleigh-Benard Convection." Journal of Fluid Mechanics 741 (February): 1-27.

[15] Tasnim, S. H., and Collins, M. R. 2004. "Numerical Analysis of Heat Transfer in a Square Cavity with a Baffle on the Hot Wall." International Communication in Heat and Mass Transfer 31 (5): 639-50.

[16] Xu, F., Patterson, J. V., and Lei, C. W. 2008. “An Experimental Study of the Unsteady Thermal Flow Around a Thin Fin on a Sidewall of a Differentially
Heated Cavity." International Journal of Heat and Fluid Flow 29 (4): 1139-53.

[17] Xu, F., Patterson, J. C., and Lei, C. W. 2009. "Transition to a Periodic Flow Induced by a Thin Fin on the Sidewall of a Differentially Heated Cavity." International Journal of Heat and Mass Transfer 52 (3-4): 620-8.

[18] Bilgen, E. 2005. "Natural Convection in Cavities with a Thin Fin on the Hot Wall." International Journal of Heat and Mass Transfer 48 (17): 3493-505.

[19] Ilis, G. G., Mobedi, M., and Oztop, H. F. 2011. "Heat Transfer Reduction due to a Ceiling-Mounted Barrier in an Enclosure with Natural Convection." Heat Transfer Engineering 32 (5): 429-38.

[20] Haghighi, A., and Vafai, K. 2014. "Optimal Positioning of Strips for Heat Transfer Reduction within an Enclosure." Numerical Heat Transfer, Part A 66 (1): $17-40$.

[21] Starner, K. E., and McManus, H. N. 1963. "An Experimental Investigation of Free Convection Heat Transfer from Rectangular Fin Arrays." Journal of Heat Transfer 85 (3): 273-7.

[22] Harahap, F., and McManus, H. N. 1967. "Natural Convection Heat Transfer from Horizontal Rectangular Fin Arrays." Transaction of the ASME 89 (1): 32-8.

[23] Jones, C. D., and Smith, L. F. 1970. "Optimum Arrangement of Rectangular Fins on Horizontal Surfaces for Free-Convection Heat Transfer." Transactions of the ASME 92 (1): 6-10.

[24] Hitt, D. L., and Campo, A. 2004. "Influence of Transverse Fins Attached to the Heated Wall of a Rayleigh-Benard Convection." ASME, International Mechanical Engineering Congress and Exposition. doi: 10.1115/IMECE2004-62124.

[25] Arquis, E., and Rady, M. 2005. "Study of Natural Convection Heat Transfer in a Finned Horizontal Fluid Layer." International Journal of Thermal Science 44 (1): 43-52.

[26] Evren-Selamet, E., Arpaci, V. S., and Borgnakke, C. 1992. "Simulation of Laminar Buoyancy-Driven Flows in an Enclosure." Numerical Heat Transfer, Part A 22 (4): 401-20.

[27] Evren-Selamet, E., and Selamet, A. 2016. "Effect of Fins on the Transition to Oscillating Laminar Natural Convection in an Enclosure." MATEC Web of Conferences 70 (August): 1-7.

[28] Ben-Cheikh, N., Campo, A., and Ourtatani, N. 2009. "Natural Convection in a Finned Rayleigh-Benard Cubical Enclosure." Presented at Int. Symp. on Convective Heat and Mass Transfer in Sustainable Energy, Tunisia. 